\title{
Cerebral Pressure Autoregulation and Vasoreactivity in the Newborn Rat
}

\author{
ANDERS PRYDS, JAN TØNNESEN, OLE PRYDS, GITTE M. KNUDSEN, AND GORM GREISEN \\ Department of Neonatology [A.P., O.P., G.G.], Neurobiology Research Unit [J.T., M.K.], Rigshospitalet, \\ 2100 Copenhagen, Denmark
}

\begin{abstract}
Perinatal brain injury has been associated with impaired cerebral blood flow (CBF) pressure autoregulation. The brain of 3- to 5-d-old rat pups is immature and similar to that of a preterm infant, and therefore we tested cerebral vasoreactivity in that animal. CBF pressure autoregulation was tested in 20 Wistar pups during normocapnia and hypercapnia, respectively. Hypotension was induced by hemorrhage and cerebral perfusion was monitored with laser Doppler flowmetry and near-infrared spectroscopy. Systolic blood pressure was measured noninvasively from the tail. During normocapnia, the autoregulatory plateau was narrow. Resting systolic blood pressure (SBP) was $39.2 \mathrm{~mm}$ $\mathrm{Hg}$ and $\mathrm{CBF}$ remained constant until SBP decreased below 36.0 $\mathrm{mm} \mathrm{Hg}$ (SE 0.8). Below the lower limit, CBF declined by a mean of $2.7 \%$ per $\mathrm{mm} \mathrm{Hg}$ [95\% confidence interval (CI), 2.4-3.0\%], and hemoglobin difference $(\mathrm{HbD})$ and total hemoglobin $(\mathrm{HbT})$ changed proportionally to $\mathrm{CBF}$. After inhalation of carbon dioxide, CBF increased significantly by a mean of $17.7 \%$ (95\% CI,
\end{abstract}

\section{ABSTRACT}

13.7-22.8\%). The CBF- $\mathrm{CO}_{2}$ reactivity was estimated to $13.4 \%$ per $\mathrm{kPa}(95 \% \mathrm{CI}, 2-24.8 \%), p=0.026$. Over the range of SBP (6-54 mm Hg), a linear relationship between CBF and SBP was found during hypercapnia, indicating abolished pressure autoregulation. A linear correlation between $\mathrm{CBF}$ and $\mathrm{HbD}$ was found $(r$ $=0.80)$. $\mathrm{CBF}$ pressure autoregulation and reactivity to $\mathrm{CO}_{2}$ operate in the newborn rat. This model may be useful for future investigations concerning perinatal pathophysiology in the immature brain. (Pediatr Res 57: 294-298, 2005)
CBF, cerebral blood flow
Abbreviations
HbD, hemoglobin difference
HbT, total hemoglobin
LDF, laser Doppler flowmetry
NIRS, near-infrared spectroscopy
SBP, systolic blood pressure

In very preterm infants, brain injury has been associated with impaired pressure autoregulation of CBF. Accordingly, periventricular hemorrhage may result from abrupt hyperperfusion whereas periventricular leukomalacia has been related to ischemia (1-9).

Cerebral pressure autoregulation refers to vascular mechanisms whereby $\mathrm{CBF}$ is held within constant levels during variations in perfusion pressure. Perfusion is thus maintained over a range of pressures by appropriate alterations in the diameter of precapillary arterioles. However, the lower limit of autoregulation is reached when the vessels become fully dilated and, beyond that point, any further decrease in pressure results in proportional drops in $\mathrm{CBF}$. Several conditions may affect the autoregulatory plateau and increased CBF as well as complete pressure passiveness secondary to vasodilatation is

Received January 8, 2004; accepted June 22, 2004.

Correspondence: Anders Pryds, M.D., Department of Neonatology, Rigshospitalet, Blegdamsvej 9, 2100 Copenhagen Ø, Denmark; e-mail:pryds@nru.dk

Supported by the Savværksejer Jeppe Juhl og hustru Ovita Juhl's Foundation gave. A.P. was supported by a scholar stipend by the H:S Research Council. The Simon Fougner Foundation donated the laser Doppler equipment.

DOI: 10.1203/01.PDR.0000148714.51310.5E observed during hypercapnia, hypoglycaemia, hypoxia, and seizure $(10-13)$.

Cerebral pressure autoregulation has been documented in several newborn animals such as piglets, lambs, and puppies (14-19). Most of these animals have rather mature brains at birth, and to compare vascular physiology with that of a preterm infant, the newborn rat pup served as a model $(20,21)$. Because we could not control ventilation in this immature animal, we evaluated the cerebrovascular response to hemorrhagic hypotension during normocapnia and carbon dioxide inhalation. The hypothesis was that pressure autoregulation operates normally in the healthy immature brain.

\section{METHODS}

Litters of 1-d-old Wistar rats together with their dams were purchased from a commercial breeder (Møllegården, Lille Skensved, Denmark). They were housed in individual cages, and all pups were reared by their dams until the experiment. The adult rats were fed a standard diet. Twenty-one pups were studied between the d 3 and 5 of life (mean, $4.1 \mathrm{~d}$ ). Their weights ranged between 8.5 and $14.1 \mathrm{~g}$ (mean, $10.8 \mathrm{~g}$ ). The Danish Animal Experiments Inspectorate approved the experimental protocol.

Preparation of animals. Anesthesia was induced by inhalation of $3.5 \%$ isoflurane with $30 \%$ oxygen. The surgical operation was performed by removal 
of the scalp for the laser Doppler probe and skin incision in the back for a temperature probe, while ECG electrodes were attached to the chest. Thereafter, isoflurane was reduced to $1 \%$ while $30 \%$ oxygen was continued, and this concentration was maintained throughout the experiment. All pups were breathing spontaneously and respiration frequency and heart rate were monitored continuously (Diascope, Simonsen \& Well Medico Technique, Albertslund, Denmark).

Doxapram was administered intraperitoneally $(2 \mathrm{mg} / \mathrm{kg} / \mathrm{h})$ to maintain normal respiration rates without apneas and hypoxic episodes.

Transcutaneous $\mathrm{PCO}_{2}\left(\mathrm{tcPCO}_{2}\right)$ and $\mathrm{PO}_{2}\left(\mathrm{tcPO}_{2}\right)$ were monitored from the abdominal skin using an electrode temperature of $44.5^{\circ} \mathrm{C}$ (TINA, Radiometer $\mathrm{A} / \mathrm{S}$, Copenhagen, Denmark). A previous study in this model has shown that $t c \mathrm{PCO}_{2}$ is reliable, whereas $\mathrm{tcPO}_{2}$ is not $(22,23)$. Normal core temperature of the rat was secured by heating pads $\left(36.7-37.3^{\circ} \mathrm{C}\right)$.

CBF was measured by LDF (Perimed 5010, Stockholm, Sweden). The equipment works with a laser light source of $780 \mathrm{~nm}$ and an interoptode distance of $250 \mu \mathrm{m}$. Using glue, the optical probe was fixed to the skull over the left parietal cortex. This procedure secured stable measurements from the same area of cerebral cortex over time.

NIRS monitored changes in oxy- $\left(\mathrm{HbO}_{2}\right)$ and deoxyhemoglobin $(\mathrm{HHb})$, which are expressed in micromolar (Niroscope, Radiometer A/S). Subsequently, changes in $\mathrm{HbT}$ and $\mathrm{HbD}$ were derived from the following formulas: $\left[\mathrm{HbO}_{2}+\mathrm{HHb}\right]$ and $\left[\mathrm{HbO}_{2}-\mathrm{HHb}\right]$. NIRS operates with four different wavelengths $(774,806,845$, and $910 \mathrm{~nm}$ ), and two optodes (fiber diameter being $3 \mathrm{~mm}$ ). A source and a receiver were placed on either side of the head corresponding to the parietal lobes.

SBP was measured noninvasively from the tail. The artery was occluded by cuff inflation, and SBP was defined as the cuff pressure when pulsatile flow, detected by another laser Doppler probe, reappeared. All calculations of SBP were performed by commercial software (Perisoft for Windows 2.10, Perimed, Stockholm, Sweden). Intra-arterial access is impossible in such animals, which is why the present technique was not evaluated with direct measurements.

Experimental protocol. Following surgical preparation, all rats were stabilized for $15 \mathrm{~min}$.

Two protocols were designed to investigate the cerebrovascular response to hemorrhagic hypotension during normocapnia and hypercapnia, respectively. At rest, baseline values for $\mathrm{CBF}, \mathrm{HbT}, \mathrm{HbD}$, and $\mathrm{SBP}$ were recorded five times over a 15-min period. Thereafter, $2000 \mathrm{IU}$ of heparin was injected subcutaneously. After another $15 \mathrm{~min}$, isoflurane was increased briefly to $3.5 \%$ and hemorrhagic hypotension was induced by amputation of the forepaw. During the experiment, SBP pressure was measured repeatedly with 2- to 3-min intervals until death from hemorrhage (Fig. 1).

Identical procedures were used in the second study. After baseline readings, the rat was held hypercapnic by increasing the inspired fraction of $\mathrm{CO}_{2}$ to $8 \%$. After another $5 \mathrm{~min}$, heparin was given (Fig. 1). The animal was decapitated at the end of each experiment.

Definitions and data analysis. $\mathrm{SBP}, \mathrm{CBF}, \mathrm{HbT}, \mathrm{HbD}$, and $\mathrm{tcPcO}_{2}$ data were converted from analog to digital and they were stored on a personal computer for later analysis. Brain laser Doppler measurements were recorded in arbitrary
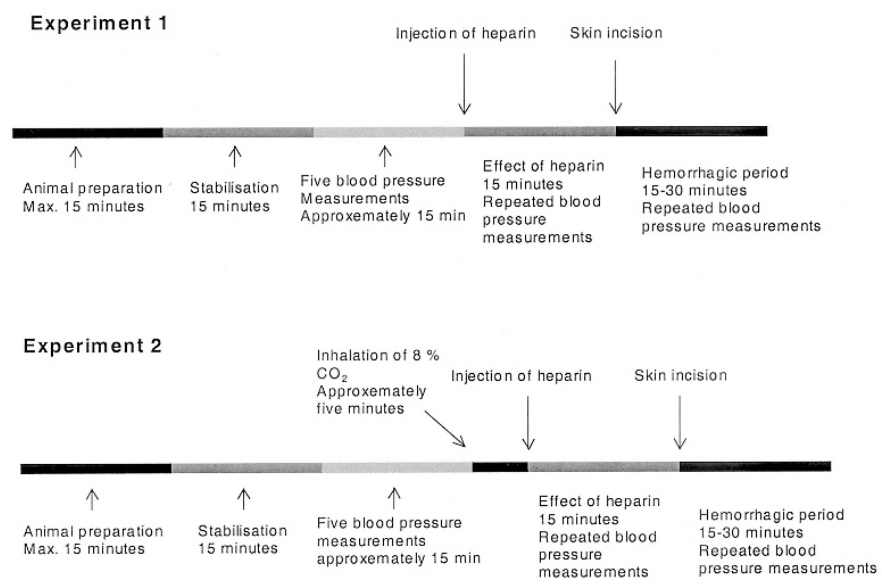

Figure 1. Protocol for the first and the second experiment. perfusion units (PU) and thus for each rat they were recoded into percentage change from the mean of the five baseline values.

Statistics. Parametric analyses were used and differences between rats and within the baseline series of five measurements were tested by means of oneand two-way ANOVA.

Pressure autoregulation and its lower limit were calculated as described by Pedersen et al. (24). In brief, the lower autoregulatory limit was obtained from the intersection of two lines found by the least square technique, and a constraint was put on the horizontal line.

The CBF-SBP and the $\mathrm{CBF}-\mathrm{CO}_{2}$ reactivities were calculated by linear regression. Because of repeated measures design, all regression analyses included one dummy variable for each rat.

The program SPSSPC 10 (SPSS Inc., Chicago, IL) was used and the level of significance was set to $p=0.05$.

\section{RESULTS}

Blood pressure. A well-defined signal from the tail laser Doppler ensured that blood pressure measurements were obtained reliably from resting conditions and until SBP dropped below approximately $15 \mathrm{~mm} \mathrm{Hg}$ (Fig. 2). Below this level, laser Doppler signals often became too noisy to allow exact calculations.

In the pups, resting SBP averaged $39.2 \mathrm{~mm} \mathrm{Hg}$ (range, 27-58 $\mathrm{mm} \mathrm{Hg}$ ). SBP values did not differ systematically from the first through the fifth measurement and the test-retest variability was calculated to $12 \%$. Similarly, resting blood pressure did not vary significantly among age groups $(3,4$, and $5 \mathrm{~d})$.

Pressure autoregulation in normocapnia. A series of 10 animals was studied successfully, and they were all alive at the end of the experiment. Blood pressures were measured approximately 25 times in each rat with simultaneous monitoring of CBF, $\mathrm{HbT}$, and $\mathrm{HbD}$. In a few rats, blood pressure declined slightly after heparin injection, most likely due to intraperitoneal bleeding, whereas the others were stable until amputation.

For the whole group, CBF remained constant until SBP decreased below $36.0 \mathrm{~mm} \mathrm{Hg}$ (SE 0.8). Thus, below the lower autoregulatory limit CBF declined in parallel with blood pressure, in mean $2.7 \%$ per mm $\mathrm{Hg}$ [95\% confidence interval (CI), 2.4-3.0\%] (Fig. 3).

Pressure autoregulation was also observed with regard to $\mathrm{HbT}$ and $\mathrm{HbD}$, respectively, as $\mathrm{HbT}$ and $\mathrm{HbD}$ were maintained until SBP decreased below $35 \mathrm{~mm} \mathrm{Hg}$ (SE 1.2). It is noteworthy that $\mathrm{HbT}$ did not increase as a result of vasodilatation as SBP declined toward the lower limit (Fig. 4).

Hypercapnia and pressure autoregulation. Eleven rats were exposed to hypercapnia during the second study. Results from one animal were discarded because of unexplained low resting blood pressure (mean, $15 \mathrm{~mm} \mathrm{Hg}$ ) leaving 10 animals for the analysis. In that group, resting SBP was slightly lower but not significantly different from values in the above study. All rats were alive during the period of study.

When $\mathrm{CO}_{2}$ was introduced, $\mathrm{CBF}$ increased by a mean of $17.7 \%$ (95\% CI, 13.7-22.8\%). From $\mathrm{tcPCO}_{2}$ readings, the CBF$\mathrm{CO}_{2}$ reactivity was estimated to $13.4 \%$ per $\mathrm{kPa}(95 \% \mathrm{CI}$, $2-24.8 \%$ ), $p=0.026$ (Fig. 5). $\mathrm{CO}_{2}$ did not affect SBP $(p=$ 0.90 ) and minor variations in SBP had no influence on CBF when SBP was incorporated as an independent variable in the multiple regression analysis (CBF-SBP reactivity: $-0.15 \%$ per $\mathrm{mm} \mathrm{Hg},(95 \% \mathrm{CI},-7.7-7.4 \%), p=0.97$; $\mathrm{CBF}-\mathrm{CO}_{2}$ reactivity: $13.5 \%$ per $\mathrm{kPa}(95 \% \mathrm{CI}, 0.2-26.7 \%), p=0.047)$. 


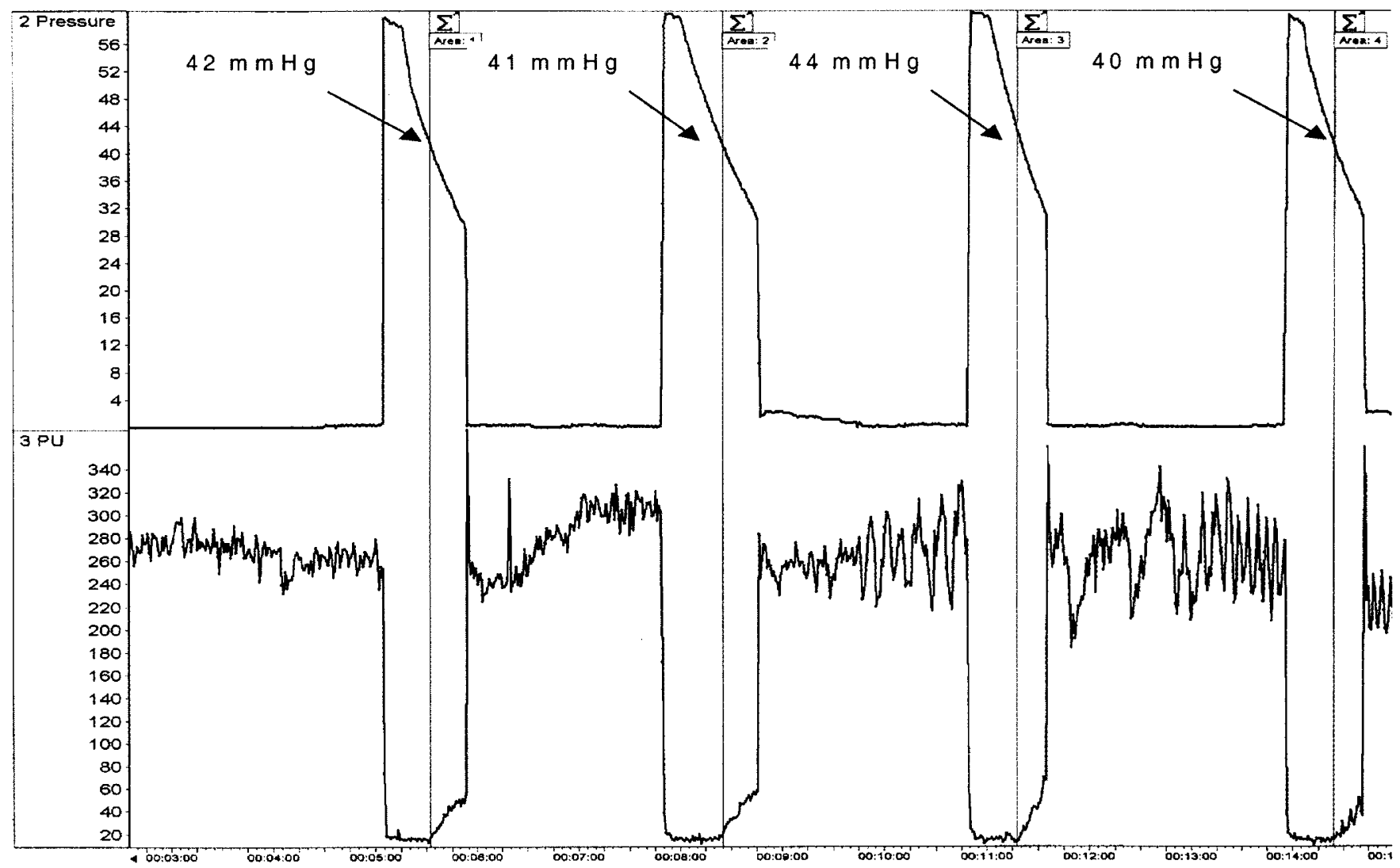

Figure 2. Four systolic blood pressure measurements calculated with Perisoft for Windows 2.10 (Perimed, Stockholm, Sweden). Cuff pressure and LDF in the tail $(P U)$ are displayed with time.

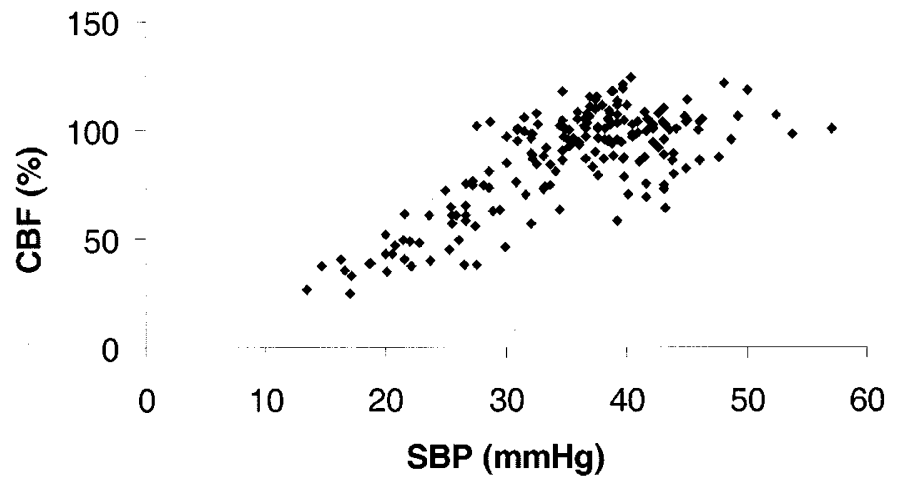

Figure 3. Changes in $\mathrm{CBF}$ during hemorrhagic hypotension in 10 normocapnic rats. Below $36.0 \mathrm{~mm} \mathrm{Hg}(\mathrm{SE}=0.8)$, CBF decreases linearly with $\mathrm{SBP}$, indicating the lower limit of pressure autoregulation $(2.7 \%$ per $\mathrm{mm} \mathrm{Hg})$.

Similarly, mean HbT increased by $0.87 \mu \mathrm{M}$ per $\mathrm{kPa}(95 \%$ CI, 0.09-1.64 $\mu \mathrm{M}), p=0.032$, whereas mean $\mathrm{HbD}$ increased by $2.94 \mu \mathrm{M}$ per $\mathrm{kPa},(95 \% \mathrm{CI}, 0.87-5.0 \mu \mathrm{M}), p=0.011$, during hypercapnia.

Pressure autoregulation under hypercapnia was not well defined, as the software detected a lower limit of $34 \mathrm{~mm} \mathrm{Hg}$ but with a very high SE of $6.9 \mathrm{~mm} \mathrm{Hg}$. Instead, a linear relation was found between CBF and SBP, and over the SBP spectrum (SBP ranging from 6 to $44 \mathrm{~mm} \mathrm{Hg}$ ), CBF declined by a mean of $2.7 \%$ per $\mathrm{mm} \mathrm{Hg}$ decrease in SBP (95\% CI, 2.0-3.4\%), $p<$ 0.001 (Fig. 6).

$\boldsymbol{H b T}$ and $\boldsymbol{H b D}$ versus $\boldsymbol{C B F}$. Changes in $\mathrm{HbT}$ were closely related to changes in $\mathrm{CBF}(r=0.86, p<0.001)$ as $\mathrm{HbT}$

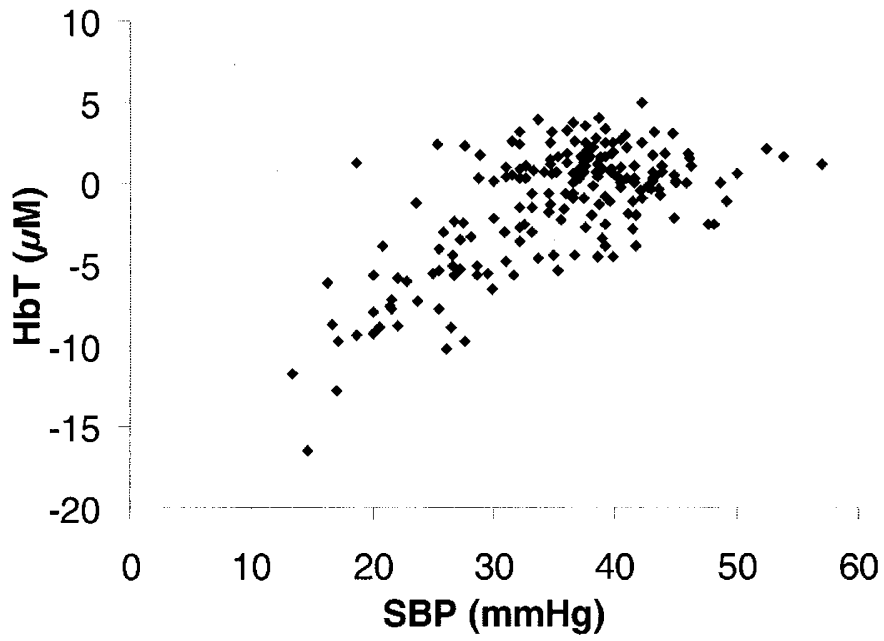

Figure 4. HbT during hemorrhagic hypotension in 10 normocapnic rats. Below 35.0 (SE 1.2) $\mathrm{mm} \mathrm{Hg}$, HbT decreases linearly with SBP, indicating the lower limit of pressure autoregulation.

increased by a mean of $0.140 \mu \mathrm{M}$ per percentage change in CBF (95\% CI, 0.126-0.153 $\mu \mathrm{M})$.

Likewise, changes in $\mathrm{HbD}$ averaged $0.227 \mu \mathrm{M}$ per percentage change in CBF (95\% CI, $0.200-0.254 \mu \mathrm{M} ; r=0.80, p<$ 0.001) (Fig. 7).

\section{DISCUSSION}

The present study demonstrates that pressure autoregulation operates in the very immature brain and that the vessels are 

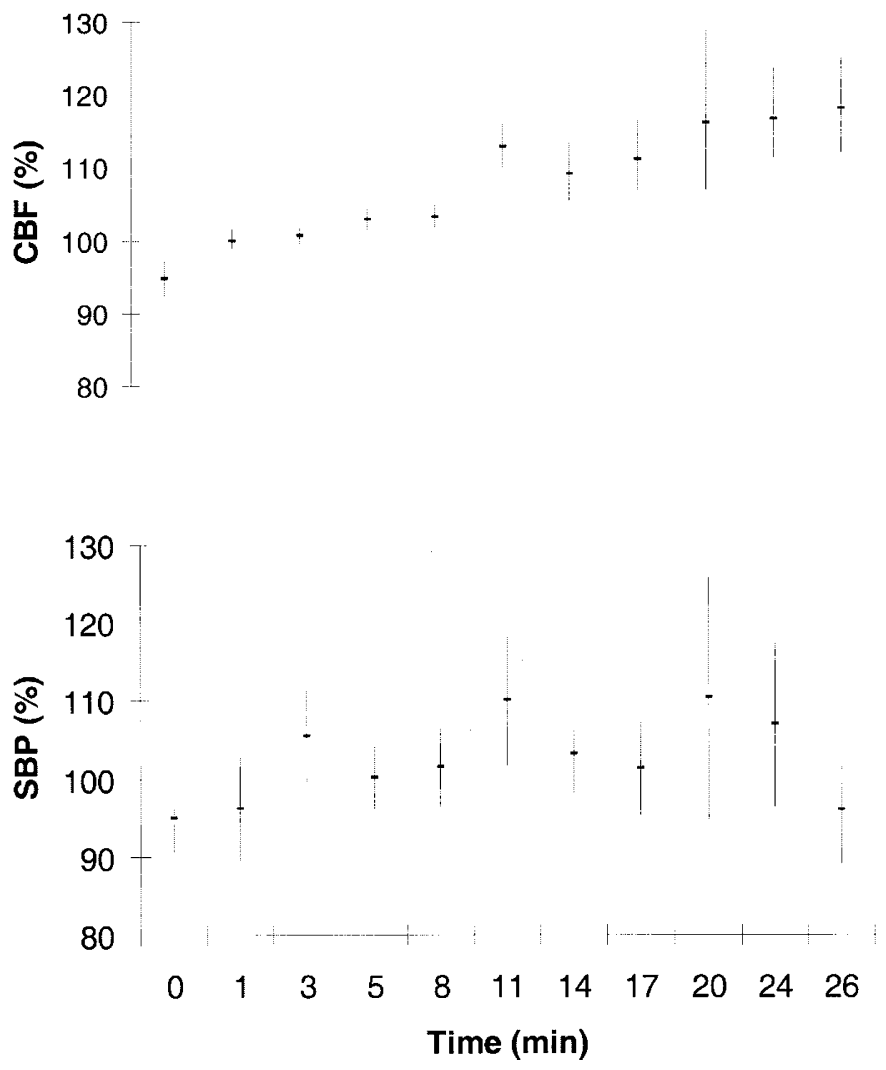

Figure 5. Response of $\mathrm{CBF}$ and $\mathrm{SBP}$ in 10 rats during hypercapnia. After five baseline recordings, $\mathrm{CO}_{2}$ was added to the inspiratory air. The data were normalized according to the average of the first five measurements. Mean values and SEM are presented.

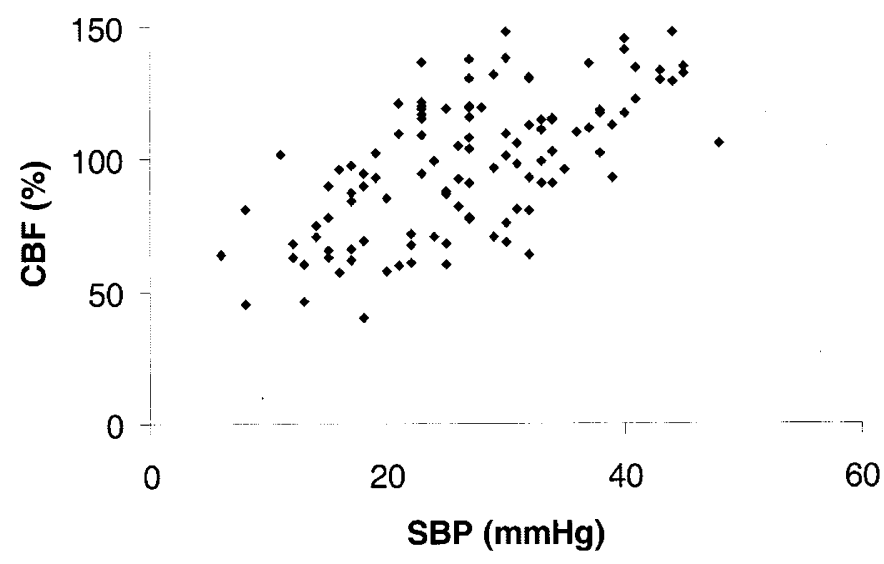

Figure 6. Changes in CBF during hemorrhagic hypotension in 10 hypercapnic rats. Over the SBP spectrum, $\mathrm{CBF}$ increased $2.7 \%$ per $\mathrm{mm} \mathrm{Hg}$ increase in SBP, indicating abolished pressure autoregulation.

responsive to $\mathrm{CO}_{2}$. During resting conditions, however, the vasodilatory reserve appears to be limited, as 1) the lower limit of pressure autoregulation is reached after a minor decrease in $\mathrm{SBP}, 2)$ the $\mathrm{CO}_{2}$ reactivity is lower than that of $21 \%$ per $\mathrm{kPa}$ observed in older animals (25), and 3) $\mathrm{HbT}$ does not increase when SBP decreases within the autoregulatory plateau. It is rational that the cerebrovascular resistance decreases by vasodilatation to ensure constant CBF levels when SBP drops toward the lower limit of pressure autoregulation. Thus, $\mathrm{HbT}$ should increase concomitantly with this vasodilatation. How-

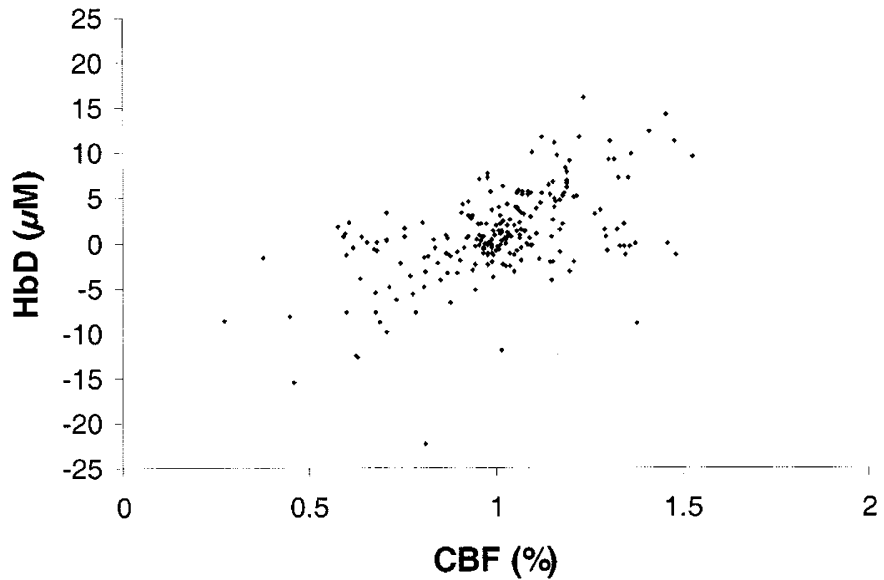

Figure 7. The relation between $\mathrm{HbD}$ and $\mathrm{CBF}$ during normocapnia and hemorrhagic hypotension $(r=0.80)$.

ever, resistance is attributed to the cerebral arterioles, which comprise $<5 \%$ of the total cerebral volume, and these minor changes in diameter may not be observed by NIRS. It should be noted that isoflurane was used for anesthesia, and this gas induces muscular relaxation and thereby cerebral vasodilatation in the mature brain (26). It is therefore possible that the cerebrovascular resistance is slightly higher in nonexperimental settings. However, a counteracting effect of doxapram is possible as mild cerebral vasoconstriction has been reported after its use (27-29).

A pressure-passive CBF occurs when blood pressure drops below the lower limit and the cerebral vascular resistance is minimal. From baseline SBP of $39.2 \mathrm{~mm} \mathrm{Hg}$ and assuming of a perfusion pressure of $35 \mathrm{~mm} \mathrm{Hg}$, pressure-passiveness implies a linear decrease in CBF of $2.9 \%$ per $\mathrm{mm} \mathrm{Hg}$. This number is almost similar to those observed in the present study during normo- and hypercapnia.

LDF was used for monitoring changes in CBF. At a wavelength of $780 \mathrm{~nm}$ and interoptode distance of $250 \mu \mathrm{m}$, light penetrates approximately $1 \mathrm{~mm}$ into tissue. The reported pressure autoregulation and $\mathrm{CO}_{2}$ reactivity therefore relate to the cortical area (30). On the other hand, changes in $\mathrm{HbT}$ and $\mathrm{HbD}$ account for all cerebral vessels, because near-infrared light penetrates the whole brain. It has been proposed that $\mathrm{HbD}$ and CBF are highly interrelated (4), and the present data support that hypothesis. The relationship between mixed vascular hemoglobin oxygen saturation ( $\mathrm{HbD}$ ) and $\mathrm{CBF}$ relies on constant cerebral artery oxygen saturation and a constant cerebral metabolic rate of oxygen $\left(\mathrm{CMRO}_{2}\right)$. The pups did not experience hypoxia during the experiment but we did not measure $\mathrm{CMRO}_{2}$, and any variations in $\mathrm{CMRO}_{2}$ may explain why changes in CBF only accounted for $64 \%$ of the variation in $\mathrm{HbD}$. Redistribution of CBF from cortical areas to midbrain structures during hypotension may be another factor. Finally, it is also possible that reductions in microvascular hematocrit resulting from shifts of fluid from the tissue into the vascular compartment may affect LDF readings during hemorrhage.

The linear relation between changes in $\mathrm{HbT}$ and $\mathrm{CBF}$ should be discussed. CBF is determined by perfusion pressure, blood viscosity, and the diameter of arteries and arterioles, whereas 
$\mathrm{HbT}$ is mainly determined by the diameter of arterioles and venules. Thus, the arteriolar diameter is the only common denominator for both $\mathrm{CBF}$ and $\mathrm{HbT}$. As a consequence, other relationships may be observed when testing pressure autoregulation using other methods than hemorrhagic hypotension. For example, small and inconsistent decreases in HbT as well as a poor relationship between $\mathrm{HbT}$ and CBF were found when systemic arterial hypotension was produced by partial occlusion of the ascending aorta (31).

It is impossible to insert arterial lines in the newborn rat, and blood pressure was measured noninvasively from the tail. A similar technique is used in commercial equipment for bigger animals. It cannot be excluded that SBP was overestimated, although an acceptable reproducibility was achieved by careful placement of the cuff and fast and reliable detection of capillary flow by LDF.

In many instances, the brain of the newborn rat is comparable to that of a preterm infant. Vannucci et al. (32) have previously reported that a 7-d postnatal pup is analogous to a premature child at 32-34 wk of gestation; i.e. cerebral cortical layering is complete, the germinal matrix is involuting, and white matter has yet to myelinate. The fact that we used slightly younger pups makes the result equivalent with conditions in even more preterm babies. Apparently, the cerebral vasoreactivity is fully developed in the immature rat pup, although we did not investigate the response to hypoxia or hypocapnia because of technical constraints with regard to mechanical ventilation. We hope that future investigations in this model may provide insight in mechanisms underlying brain pathology in sick preterm infants, especially with regard to periventricular hemorrhage and leukomalacia.

Acknowledgments. The authors thank Professor Olaf Paulson for assistance with the application of the software to estimate the lower autoregulatory limit.

\section{REFERENCES}

1. Volpe JJ 1997 Brain injury in the premature infant. Neuropathology, clinical aspects, pathogenesis, and prevention. Clin Perinatol 24:567-587

2. Pryds O 1991 Control of cerebral circulation in the high-risk neonate. Ann Neurol 30:321-329

3. Pryds O, Greisen G, Lou H, Friis-Hansen B 1989 Heterogeneity of cerebral vasoreactivity in preterm infants supported by mechanical ventilation. J Pediatr 115:638645

4. Tsuji M, Saul JP, du Plessis A, Eichenwald E, Sobh J, Crocker R, Volpe JJ 2000 Cerebral intravascular oxygenation correlates with mean arterial pressure in critically ill premature infants. Pediatrics 106:625-632

5. Fujimura M, Salisbury DM, Robinson RO, Howat P, Emerson PM, Keeling JW, Tizard JP 1979 Clinical events relating to intraventricular haemorrhage in the newborn. Arch Dis Child 54:409-414
6. Cooke RW 1981 Factors associated with periventricular haemorrhage in very low birthweight infants. Arch Dis Child 56:425-431

7. Levene MI, Fawer CL, Lamont RF 1982 Risk factors in the development of intraventricular haemorrhage in the preterm neonate. Arch Dis Child 57:410-417

8. Volpe JJ 1989 Intraventricular hemorrhage in the premature infant-current concepts. Part I. Ann Neurol 25:3-11

9. Volpe JJ 1989 Intraventricular hemorrhage in the premature infant-current concepts. Part II. Ann Neurol 25:109-16

10. Haggendal E, Johansson B 1965 Effects of arterial carbon dioxide tension and oxygen saturation on cerebral blood flow autoregulation in dogs. Acta Physiol Scand Suppl 258:27-53

11. Plum F, Posner JB, Troy B 1968 Cerebral metabolic and circulatory responses to induced convulsions in animals. Arch Neurol 18:1-13

12. Nilsson B, Agardh CD, Ingvar M, Siesjo BK 1981 Cerebrovascular response during and following severe insulin-induced hypoglycemia: $\mathrm{CO}_{2}$-sensitivity, autoregulation, and influence of prostaglandin synthesis inhibition. Acta Physiol Scand 111:455-463

13. Paulson OB, Strandgaard S, Edvinsson L 1990 Cerebral autoregulation. Cerebrovasc Brain Metab Rev 2:161-192

14. Szymonowicz W, Walker AM, Yu VY, Stewart ML, Cannata J, Cussen L 1990 Regional cerebral blood flow after hemorrhagic hypotension in the preterm, nearterm, and newborn lamb. Pediatr Res 28:361-366

15. Laptook A, Stonestreet BS, Oh W 1982 Autoregulation of brain blood flow in the newborn piglet: regional differences in flow reduction during hypotension. Early Hum Dev 6:99-107

16. Hernandez MJ, Brennan RW, Bowman GS 1980 Autoregulation of cerebral blood flow in the newborn dog. Brain Res 184:199-202

17. Pasternak JF, Groothuis DR 1985 Autoregulation of cerebral blood flow in the newborn beagle puppy. Biol Neonate 48:100-109

18. Tweed WA, Cote J, Wade JG, Gregory G, Mills A 1982 Preservation of fetal brain blood flow relative to other organs during hypovolemic hypotension. Pediatr Res 16:137-140

19. Szymonowicz W, Walker AM, Cussen L, Cannata J, Yu VY 1988 Developmental changes in regional cerebral blood flow in fetal and newborn lambs. Am J Physiol 254:H52-H58

20. Himwich WA 1973 Problems in interpreting neurochemical changes occurring in developing and aging animals. Prog Brain Res 40:13-23

21. Whitelaw A, Thoresen M 2000 Antenatal steroids and the developing brain. Arch Dis Child Fetal Neonatal Ed 83:F154-157

22. Fumagalli M, Mosca F, Moos Knudsen G, Greisen G 2004 A newborn rat model for the study of cerebral hemodynamics by near-infrared spectroscopy and laser-Doppler flowmetry in the immature brain. Biol Neonate 85:112-120

23. Fumagalli M, Mosca F, Knudsen GM, Greisen G 2004 Transient hyperoxia and residual cerebrovascular effects in the newborn rat. Pediatr Res 55:380-384

24. Pedersen TF, Paulson OB, Nielsen AH, Strandgaard S 2003 Effect of nephrectomy and captopril on autoregulation of cerebral blood flow in rats. Am J Physiol Heart Circ Physiol 285:H1097-H1104

25. Golding EM, Steenberg ML, Contant CF Jr., Krishnappa I, Robertson CS, Bryan RM Jr 1999 Cerebrovascular reactivity to $\mathrm{CO}(2)$ and hypotension after mild cortical impact injury. Am J Physiol 277:H1457-H1466

26. Lee JG, Hudetz AG, Smith JJ, Hillard CJ, Bosnjak ZJ, Kampine JP 1994 The effects of halothane and isoflurane on cerebrocortical microcirculation and autoregulation as assessed by laser-Doppler flowmetry. Anesth Analg 79:58-65

27. Nehlig A 1994 Effects of respiratory stimulants on cerebral metabolism and blood flow. Biol Neonate 65:258-264

28. Kuroda Y, Murakami M, Tsuruta J, Murakawa T, Shiroyama Y 2000 Effects of sevoflurane and isoflurane on the ratio of cerebral blood flow/metabolic rate for oxygen in neurosurgery. J Anesth 14:128-134

29. Gross PM, Marcus ML, Heistad DD 1980 Regional distribution of cerebral blood flow during exercise in dogs. J Appl Physiol 48:213-217

30. Fabricius M, Akgoren N, Dirnagl U, Lauritzen M 1997 Laminar analysis of cerebral blood flow in cortex of rats by laser-Doppler flowmetry: a pilot study. J Cereb Blood Flow Metab 17:1326-1336

31. Tsuji M, duPlessis A, Taylor G, Crocker R, Volpe JJ 1998 Near infrared spectroscopy detects cerebral ischemia during hypotension in piglets. Pediatr Res 44:591-595

32. Vannucci RC, Towfighi J, Heitjan DF, Brucklacher RM 1995 Carbon dioxide protects the perinatal brain from hypoxic-ischemic damage: an experimental study in the immature rat. Pediatrics 95:868-874 